\title{
Evolução do desenvolvimento socioeconômico da América Latina - Período 2000 - 2012
}

\author{
José Flávio Messias e José Ultemar da Silva² \\ Recebido em: 10/10/2013. Aprovado em: 18/11/2013. Disponibilizado em: 20/12/2013 \\ 1. Doutor Ciências Sociais / Relações Internacionais - PUC/SP. Professor do Departamento de Ciências Gerencias Uninove SP \\ E-mail: jflavio@uninove.br. \\ 2. Pós-Doutor em Administração / USP. Doutor em Ciências Sociais / Relações Internacionais PUC/SP. Professor do \\ Departamento de Ciências Gerencias Uninove_SP.
}

\section{Resumo}

O objetivo dessa pesquisa é refletir sobre as mudanças ocorridas no sistema econômico como um todo, mais especificamente osimpactos gerados nas estruturas sociais e o agravamento de suas vulnerabilidades, decorrentes do acirramento da concorrência e da consequente pulverização da produção. O rápido avanço tecnológico e a busca contínua de vantagens comparativas em torno do planeta fragmentam a produção, que, por sua vez, flexibilizam o trabalho e reduzem o emprego, ou seja, diminui-se a mão de obra necessária no processo, em razão da mecanização e da robotização dos processos, gerando um contingente de excluídos do sistema.

Tendo como pano de fundo as discussões travadas na condução da economia, em torno da questão da pobreza, do desenvolvimento socioeconômico e dos mecanismos de (re)inserção da população no sistema econômico, mediante análise das contribuições de pesquisadores de instituições públicas e privadas, vamos focar as políticas sociais implementadas em alguns países da América Latina, por meio dos Programas de Transferência Condicionada de Renda (PTCRs), que visam atenuar parcialmente os níveis de pobreza e as desigualdades existentes, além de avaliar os resultados obtidos da implantação desses programas, em contraponto a crise financeira internacional iniciada em 2009, que desencadeou sérios problemas sócio-econômicos, inclusive nos países ricos.

Palavras-chave: Desemprego, Desenvolvimento econômico, Vuleabilidades Sociais, Políticas sociais, Crise Financeira Internacional.

\footnotetext{
Abstract

A evolution of the development of socio-economic in latin america 2000 - 2012. The objective of this research is to reflect on the changes in the economic system as a whole, specifically the impacts on social structures and the deterioration of their vulnerabilities arising from increased competition and the resulting spray of production. The rapid technological advance and the continued search for comparative advantages around the planet fragment production, which in turn make flexible working and reduce employment, or reduces the manpower needed in the process, due to mechanization and robot processes, generating a number of deleted from the system. Set against the
} 
background of discussions on driving the economy, around the issue of poverty, socio-economic development and the mechanisms of (re) integration of population into the economic system, by analyzing the contributions of researchers from public and private institutions let's focus on social policies implemented in some Latin American countries, through programs Cash Transfer - PTCRs, partly aimed at alleviating poverty levels and inequalities and evaluate the results arising from their deployment, in contrast to the international financial crisis started in 2009, which triggered serious socio-economic problems, including in rich countries.

Keywords: Economic development, Social Policy, Social vulnerability, Unemployment, Internacional Financial crisis. 


\section{Introdução}

O objetivo desse artigo é analisar o nível de desenvolvimento socioeconômico que se encontram os principais países da América Latina, uma vez que nas últimas décadas houve um grande esforço para obter uma maior inserção e integração nas relações comerciais e financeiras internacionais, assim como foram implementadas, com sucesso, diversas políticas sociais compensatórias, por meio de Programas deTransferência Condicionada de Renda (PTCRs), atenuando parcialmente os níveis de pobreza e as desigualdades de renda existentes na região, melhorando também outros indicadores relacionados às Metas do Milênio, estabelecidas pela Organização das Nações Unidas - ONU . Firmado por 191 paísesmembros da Organização das Nações Unidas (ONU), em 2000, esses objetivos foram subdivididos nas chamadas "Oito Metas do Milênio", entre elas acabar com a fome e a miséria, reduzir a mortalidade infantil, qualidade de vida e respeito ao meio ambiente, a erradicação de doenças, entre outros, até 2015.

Cabe salientar que a crise financeira internacional iniciada em 2008, influenciou negativamente $O$ avanço obtido nos indicadores sociais até então, pois desencadeou uma forte recessão, notadamente nos países desenvolvidos, refletindo sobre a demanda dos produtos importados da região. Sendo assim, inicialmente faremos uma breve discussão sobre os conceitos relacionados ao desenvolvimento e seus desdobramentos e o papel atenuador das políticas sociais no combate as distorções geradas pelo sistema capitalista de produção, e, num segundo momento, mostrar a importância da Comissão Econômica para América Latina (CEPAL) na busca de um maior entendimento sobre os problemas estruturais e do planejamento econômico para equacioná-los.Finalmente, analisaremos os principais fatores estruturais vigentes no contexto econômico latino-americano e seus reflexos desencadeados na sociedade latina americana como um todo, por meio da análise comparativa dos principais indicadores.

O objetivo dessa pesquisa é refletir sobre as mudanças recentes ocorridas no sistema econômico como um todo, notadamente os reflexos desencadeados nas estruturas sociais e suas vulnerabilidades, decorrentes da flexibilização do modo de produção, incidindo sobre o trabalho e o emprego, mediante contribuições de pesquisadores, análises de instituições nacionais e internacionais e do poder público, tendo como pano de fundo as discussões travadas na condução da economia, em torno da questão da pobreza, do desenvolvimento socioeconômico e dos mecanismos de (re) inserção da população no sistema econômico, sobretudo no período posterior a crise financeira internacional de 2008, que provocou uma forte retração da demanda e do fluxo de investimentos e as medidas anticiclicas que os governos da região estão tomando para tentar superar a crise.

\section{Justificativa}

As transformações econômicas que se iniciaram na década de 1970 produziram mudanças radicais na relação entre capital e trabalho, de forma que afetou tanto a estrutura quanto a capacidade de geração de emprego.

Em decorrência da crise de demanda e da inflação gerada pela crise do petróleo, houve uma queda no ritmo da produtividade e da elevação do capital-produto, gerando a necessidade da adoção de novas formas de organização pelas empresas. 
O novo padrão, denominado pósfordista, adotou uma estratégia mais flexível e individualizada, fundamentada numa forte inovação tecnológica e descentralização produtiva.

Os ganhos de produtividade têm reduzido drasticamente o número de postos de trabalho e, mesmo que parte desse contingente de pessoas venha a ser absorvido pelo setor de serviços, ainda é insuficiente para reverter à tendência de redução do nível de desemprego e do grau de vulnerabilidade instaurado.

O processo concorrencial vigente, com base nas leis de mercado, norteia-se pela perspectiva utilitarista, cujo objetivo é à maximização do próprio bem-estar, em detrimento da promoção do bem-estar do grupo social estabelecido, quebrando laços de solidariedade e de defesa dos interesses comuns consolidados após a segunda guerra, por meio das Políticas Keynesianas, que obtiveram as maiores taxas de crescimento da economia internacional.

Sendo assim, cabe investigar como essas mudanças têm refletido nas definições políticas a serem implementadas, nas ideologias e nos modelos de gestão econômica, avaliando alternativas de como mensurar e/ou atenuar os graves problemas sociais existentes.

\section{Metodologia}

Trata-se de uma pesquisa bibliográfica, abordando a evolução dos modelos econômicos e o papel das políticas sociais na busca do desenvolvimento econômico, a inserção socioeconômica, o trabalho e o emprego, o papel do Estado, etc.; avaliando, num segundo momento, o impacto sofrido pelas transformações ocorridas no período pós-fordista a partir da década de 1970, que desencadeou numa forte reestruturação no setor produtivo, e, consequentemente, no nível de emprego, gerando uma forte vulnerabilidade social na população como um todo e o questionamento das políticas relacionadas ao welfare state e suas formas de financiamento.

\section{Desenvolvimento econômico: conceitos básicos}

A noção de “[...]desenvolvimento econômico constitui um processo histórico de crescimento sustentado de renda ou do valor adicionado por habitante visando a melhoria do padrão de vida da população de um determinado estado nacional resultante da sistemática acumulação de capital e da incorporação de conhecimento ou progresso técnico à produção" ( PEREIRA, 2006, p. 209).

Não existe desenvolvimento sem o crescimento do produto e da renda média, embora esses não sejam suficientes para determinar se, de fato, existe desenvolvimento socioeconômico num determinado país ou região. Efetivamente precisamos avaliar se os benefícios do crescimento foram extendidos a todos os cidadãos. Para tanto, outros indicadores se fazem necessários, tais como as condições de moradia, saneamento básico, educação, saúde, lazer, etc, ou seja, a melhoria das condições de vida da população (Messias \& Silva, 2010).

Numa perspectiva histórica, observamos vários períodos em que o desenvolvimento econômico era concentrador de renda, embora tenha ocorrido uma melhoria no padrão de vida médio. No entanto, não existe uma distribuição equilibrada dos beneficios do desenvolvimento, geralmente os trabalhadores mais qualificados recebem 
salários maiores, enquanto trabalhadores sem qualificação podem receber baixos salários, na medida em que exista mão de obra abundante.

Sendo assim, do ponto de vista ético, o desenvolvimento não pode ser entendido como único objetivo político. Nesse sentido, Pereira (2006) afirma que a manutenção da segurança pública, liberdade e justiça social, implicando uma distribuição de renda mais equitativa são tão importantes quanto a busca do próprio desenvolvimento pelos diversos estados nacionais.

Os mecanismos de proteção social ganharam um novo impulso no período posterior à Segunda Guerra Mundial, quando os benefícios foram estendidos a todos os cidadãos, e, não só aos assalariados, passando a atender os problemas de saúde e de desemprego, constituindo, nesse sentido, num fator distribuidor de renda, aproximando-se do que hoje se entende por Seguridade Social. Paradoxalmente, apesar do ciclo de expansão e crescimento dos países industrializados obtidos a partir de 1960, surgem novas indagações sobre justiça social, com base em questionamentos em termos de ritmo, tendência e concentração de renda.

A questão da distribuição de renda transforma-se novamente em um dos pontos mais discutidos da teoria econômica. Ela passa a incorporar as considerações sobre a implementação de políticas, programas e projetos governamentais, ultrapassando os limites de eficácia econômica, assumindo a responsabilidade de enunciar julgamentos de valor sobre a distribuição de renda e o bemestar social (MOURA: 1981, in TÔRRES, 1985).

De acordo com o autor, um nível mínimo de renda na sociedade pode representar uma espécie de segurança para todos, e, essa motivação pode levar os indivíduos a preferirem uma taxação maior que qualquer programa governamental de distribuição de renda. Nesse contexto, as contribuições de Rawls (1997) distanciam das formulações propostas por seus contemporâneos, inserindo a ideia de justiça redistributiva em uma política de democratização de oportunidades.

A partir dos postulados de que o indivíduo ignora sua posição na estrutura social, o autor introduz o conceito de igualdade de oportunidades, ao afirmar que todas as pessoas têm direitos iguais ao acesso amplo de liberdades básicas, compatíveis com planos de liberdades para todos. No processo de correção dessas desigualdades, que seria realizado por instituições sociais que permitiriam obter o máximo de bem-estar aos menos favorecidos. Paralelamente ao plano econômico, temos também a questão da satisfação do mínimo social como função do governo, sem, todavia, constituir essa função num investimento constante nem trazer prejuízos à ordem econômica, conforme crítica realizada por Rawls (Messias \& Silva, 2010).

Entre essas funções, estariam o controle do salário mínimo, políticas sociais em habitação, educação, saúde etc, além do atendimento aos grupos excluídos ou menos favorecidos no mercado de trabalho. A partir desse momento, passa-se a avaliar as defasagens na distribuição de renda no interior de uma mesma sociedade.

[...]a etapa de desenvolvimento econômico e social no interior de cada sociedade vai condicionar a própria noção de limite de pobreza absoluta ou de mínimo vital - indo da garantia das necessidades primárias - o mínimo em nutrição, o abrigo indispensável - até se pleitear por uma política de igualdade de oportunidades e o desenvolvimento integral da personalidade(TÔRRES, 1985, p.9).

Em seguida, em termos de escala, enquanto que nas sociedades industrializadas o estado de pobreza 


\begin{abstract}
absoluta é restrito a uma camada minoritária, nos países não industrializados, ou em vias de industrialização, este estado se transforma em um fenômeno de massa(TÔRRES, 1985, p. 9).
\end{abstract}

Nas duas situações, os limites extremos relacionados à distribuição de renda constituem a escala da medida de desigualdades sociais e limite de pobreza absoluta mais utilizada no interior de cada sociedade.

A partir desse momento, a família passou a constituir um dos pilares básicos na luta contra a pobreza, sendo objeto central das políticas sociais, tanto nos países em desenvolvimento quanto países industrializados - destacando-nos que os dados agregados por família ocupam um lugar importante nas estimativas dos indicadores sociais.

Num contexto em que as pessoas não possuam condições satisfatórias para o exercício da cidadania, como educação, saúde, entre outros, essa vertente admite a existência da Seguridade Social, desde que as vantagens sociais do sistema impulsionem a riqueza social no longo prazo, estendendo os benefícios para um número maior de pessoas.

Tendo em vista a justiça social, que leve em consideração a existência dos direitos, dos méritos e de suas necessidades, sem enfatizar os próprios conflitos existentes na sociedade, decorrentes das relações individuais entre si, é incompatível, pressupondo uma sociedade idealizada, sem suas contradições e a existência de interesses antagônicos.

Segundo Abranches (1994), caso a política pudesse ser tratada apenas como um contrato, a política social seria uma cláusula irrevogável do capítulo das obrigações coletivas a cargo do Estado. No entanto, a política está diretamente ligada ao conflito, oposição e contradição de interesses. O conflito negociado, regulado por instituições políticas de naturezas diversas, condicionadas por mediações que tornam possível reduzir os antagonismos e projetá-los em um movimento positivo. A política social pode ser contextualizada, inicialmente, do ponto de vista do Estado, como uma proposta planejada de enfrentamento das desigualdades sociais. Quem detém instrumentos eficazes de pressão tem mais chances de obter mais da ação do Estado do que aqueles dependentes dessa própria ação para conseguir o mínimo indispensável à sua sobrevivência.

Nas situações em que não houver abundância plena de recursos e não se tenha atingido um patamar significativo de justiça distributiva, a realização de objetivos de acumulação envolvem sacrifícios em relação ao consumo individual em detrimento do no consumo coletivo e pode, dependendo da correlação de poder vigente, impor pesadas privações àqueles destituídos de recursos próprios de defesa.

A Política Social intervém no hiato derivado dos desequilíbrios na distribuição em favor da acumulação e em detrimento da satisfação de necessidades sociais básicas, assim como na promoção da igualdade. A ação social do Estado diz respeito tanto à promoção da justiça social, quanto ao combate à miséria, embora sejam distintos... No primeiro caso, a busca da equidade se faz, comumente, sob a forma da garantia e promoção dos direitos sociais da cidadania. No segundo, a intervenção do Estado se localiza, sobretudo, no campo definido por escolhas políticas quanto ao modo e ao grau de correção de desequilíbrios sociais, através de mudanças setoriais e reformas estruturais baseadas em critérios de necessidade (ABRANCHES, 1994 p.11). 
Podemos concluir que as políticas sociais possuem como objetivo básico promover a justiça social e tentar minimizar as disparidades sociais e econômicas, por meio da atuação do Estado - de forma compensatória e/ou redistributiva da renda, garantindo assim a cidadania à população carente.

Pochmann (1997), aponta alguns tipos de políticas ativas e passivas que podem ser implementadas no Brasil, e, em razão do país não se constituir numa economia totalmente industrializada, também poderiam ser implementadas nos países que integram a América Latina, dada a simililaridade e os problemas comuns existentes entre eles. Essas políticas citadas pelo autor são as políticas ativas e as políticas compensatórias.

As políticas ativas podem ser divididas em cinco modalidades:

a) Elaboração de um projeto nacional, capaz de definir as linhas gerais de crescimento econômico e justiça social, tendo o emprego como uma questão central;

b) Reforma agrária, pois ela possui efeitos positivos na geração de emprego no campo;

c) Desconcentração de renda, que possibilita o surgimento de novos consumidores e estimula a geração de empregos nos setores secundário e terciário;

d) Retomada dos investimentos em infraestrutura material, com o objetivo de renová-la e completá-la em todo o país (saneamento, habitação, etc.) pois tais investimentos são portadores de efeitos multiplicadores sobre o nível de atividade em vários setores; e) Serviço social, como programa de utilidade coletiva, melhoria da qualidade dos serviços públicos, ampliação das atividades de parceria entre as comunidades de assistência e de prestação de serviços, bem como programas de estágios, de garantia de renda, de educação, saúde e previdência.

As políticas compensatórias podem ser divididas em três modalidades:

a) Implantação de uma agência pública de emprego, com capacidade de reunir: (1) a intermediação de mão de obra, (2) o atendimento dos benefícios sociais e (3) a formação e qualificação de trabalhadores;

b) Reformulação do sistema do seguro-desemprego, proporcionando a diferenciação dos benefícios conforme o perfil do desempregado (chefe de família, idoso, sem qualificação), assim como a criação de um novo programa de integração salarial para os desempregados em caráter estrutural e treinamento para possibilitar sua reinserção no mercado;

c) Introdução de um sistema democrático de relações de trabalho, tentando reduzir a precarização do trabalho, a rotatividade e a informalidade.

As alternativas propostas por Pochmann (1997), apontam para a necessidade de um órgão regulador nos moldes que precederam a crise vigente no mercado de trabalho. $\mathrm{O}$ diálogo e o vínculo entre os diversos atores econômicos e as instituições supranacionais e o próprio Estado foram perdidos - as empresas tentam sobreviver na concorrência 
estabelecida em caráter mundial, o papel e o campo de atuação do Estado está sendo reduzido drasticamente e os trabalhadores sofrem as consequências da produtividade levada ao extremo, sendo considerada como um fim em si mesma.

A qualidade do Estado para a execução das políticas públicas baseia-se diretamente no grau de organização da cidadania. $\mathrm{Na}$ falta de uma sociedade civil organizada, o que observamos, é a manipulação da população, cujo reflexo é a pobreza política, em que não existe a presença consciente do assistido. $\mathrm{O}$ avanço da vertente liberal na maioria dos países, tem afetado drasticamente os sistemas que visam reduzir dos desníveis sociais e/ou o atendimento de algumas necessidades básicas das camadas mais carentes da população. Embora deva existir um equilíbrio entre receitas, despesas e racionalidade na gestão dos recursos disponíveis, a utilização da lógica do mercado para o enfrentamento das questões sociais parece-nos incompatível, principalmente com tantos problemas pendentes para serem resolvidos. Numa sociedade organizada , a dicotomia público/privado possui uma linha demarcatória mais sutil, diferente da visão do capitalismo versus socialismo. Há uma maior participação das Organizações não Governamentais (ONGs), de forma que a sociedadade civil passa a ter uma participação mais atuante. Nesse contexto, o debate entre liberais e desenvolvimentistas sobre o tamanho do Estado cede espaço para a discussão sobre governabilidade e sua capacidade de gestão. Segundo Pinheiro (1995), o Estado capaz, é aquele que reúne as condições de governabilidade para promover os ajustes necessários na estrutura produtiva, buscando um novo modelo de desenvolvimento.

A nova conjugação de forças observa a perpetuação de atores políticos antigos, que sobrevivem no poder um modelo após o outro, assim como proporciona também o surgimento de novos atores provenientes dos setores organizados da sociedade, como as organizações não governamentais (ongs) e empresas públicas e privadas que adotam mecanismos de governança corporativa e ampliam suas ações sociais visando a melhoria da comunidade e ações de responsabilidade social (LODI, 2000). Notamos então, uma inversão na concessão do subsídio: ao invés de subsidiar a oferta por meio de pagamento aos prestadores de serviços de saúde ou do ensino gratuito, o Estado financiaria a demanda por meio de cupons ou bolsas aos mais carentes, promovendo a descentralização das atividades, transferindo a decisão sobre a alocação de recursos à esferas subestatais (atores não governamentais e sujeitos ao controle social dos agentes envolvidos no processo). O novo paradigma concentra-se em produzir mais impacto na população, focando o indicador custo-impacto. $\mathrm{O}$ novo Estado direciona o gasto social para os grupos mais necessitados, de forma a amortecer a implementação das políticas de ajuste, operacionalizando o novo modelo econômico por meio da preservação do tecido social e da capacidade do governo, reforçando assim uma imagem externa favorável e otimista para a atração de capitais externos e a manutenção das estruturas clientelísticas de manutenção do poder (Messias \& Silva, 2010).

\section{Políticas Sociais implementadas nos países da América Latina}

Os países da América Latina tradicionalmente apresentam uma combinação de altos níveis de pobreza e de desigualdade social e de renda. Os níveis de pobreza persistem em razão das baixas taxas de crescimento econômico, combinando com outros fatores que ampliam a exclusão 
social: educação, saúde, moradia, etc. (CEPAL, 2006). Um fator apontado como importante para a melhoria nos indicadores de pobreza foi a implementação em vários países, de programas de transferência de renda condicionadas, que visam, de imediato, atenuar a falta de recursos das famílias mais pobres e atuar, no médio prazo, no rompimento do ciclo de pobreza - que exigem frequência escolar e a utilização de serviços de saúde para a família.

Os países que mais se destacaram nas melhorias obtidas com a impantação das políticas de transferência de renda condicionadas foram o Brasil, o Chile e o México.

O Brasil adotou o Bolsa Família em 2003, que consolidou quatro programas de transferência de renda preexistentes: o Programa de Erradicação do Trabalho Infantil (1996), o Bolsa Escola (2001), o Bolsa Alimentação(2003) e o Vale Gás, que não exigia a contrapartida, que possibilitou o acesso de produtos e serviços essenvciais para a melhoria da qualidade de vida da população carente (Messias \& Silva, 2010).

O Chile adotou o programa Chile Solidário em 2002, como sistema de proteção a 225 famílias extremamente pobres, composto por : apoio às famílias, subsídios monetários e acesso prioritário à programas de proteção social. O modelo mexicano conta com uma fórmula complexa, que dependendo do nível escolar da família beneficiada, das crianças que estão matriculadas na escola e da composição etária do domicílio, paga até 1.095 pesos (cerca de $\mathrm{R} \$ 175,00)$ por família com filhos no primeiro ciclo escolar e 1.855 pesos ( cerca de $\mathrm{R} \$$ $300,00)$ às famílias com filhos no secundário (Messias \& Silva, 2010).

Embora sendo responsável por uma pequena parte da renda total, “[...] a focalização dos Programas de Transferência de Renda Condicionalidades - PTRCs é otima, o impacto sobre a desigualdade equivale a $21 \%$ da queda de 2,7 pontos de Gini observada tanto no Brasil como no México. No Chile, a contribuição foi de 15\% de uma queda muito mais modesta de 0,1 ponto de Gini" (SOARES, in GARSCHAGEN, 2007, p. 34).

Adotando-se uma perspectiva de longo prazo, comparando-se dados de 1990 com os obtidos pela Cepal em 2006, vericamos que a taxa de pobreza caiu $11,8 \%$ e a de indigentes $9,1 \%$, o que significa uma redução de 20 milhões de pessoas no que se refere a esse item. Neste período, foi a primeira vez que o número de pobres ficou abaixo de 200 milhões de habitantes. Essa tendência de queda da população em estado de pobreza foi mantida: 184 milhões em 2009, 176 milhões em 2010, 168 milhões em 2011 e 167 milhões em 2012 (Panorama Social A, Latina, pag. 14, 2012).

De acordo com estudos da Cepal, o nível de gastos públicos sociais aumentou 10\% entre os anos de 2002 e 2003 e 2004 e 2005, atingindo US\$ 660 per capita, com base no valor do dólar americano do ano de 2000. Entretanto há grandes disparidades de gastos entre os países analisados. A diferença entre o gasto por habitante é 15 vezes maior entre o país que mais investe em relação ao que menos gasta. Existe também uma concentração em programas dirigidos contra a pobreza que se utilizam de mecanismos de transferência de renda condicionadas (Messias \& Silva, 2010). Com o advento da crise, muitos países ampliaram os gastos sociais a fim de evitarem uma retração ainda maior da economia, procurando estabilizar a demanda, passando de $16,6 \%$ do PIB no período $2007 / 8$ para $18,6 \%$ no perído 2009/10 (CEPAL, 2012). Um dos grandes desafios das políticas sociais, num segundo momento, é que os assistidos passem a gerir suas vidas, quebrando o ciclo de dependência dos recursos públicos. Para que ocorresse essa mudança de patamar, a capacitação 
profissional seria fundamental para proporcionar a inserção do individuo no mercado de trabalho e obter renda suficiente para garantir a sua subsistência.

\section{Condicionantes estruturais na economia América Latina}

Desde o término da Guerra Fria, reacendeu-se a controvérsia mercado/ planejamento, na medida em que os países que formavam o ex-mundo socialista transformaram-se em fronteiras de expansão do capitalismo. Da queda do muro de Berlim à extinção do Pacto de Varsóvia; da demolição do império soviético à desagregação da Iugoslávia; do tratado de Maastricht (União Europeia) ao Nafta, enfim, uma série de fatos que ocorreram, numa velocidade impressionante, alterando o curso da história contemporânea. Embora o planejamento governamental tenha sido utilizado largamente, na fase de reconstrução das economias nacionais (notadamente no período posterior à segunda guerra) e de industrialização substitutivas de importação, adotadas nos países do terceiro mundo, iniciou um processo de queda livre, reforçado a partir da crise do bloco soviético. Não obstante, em novembro de 1989, reuniram-se na capital dos Estados Unidos, funcionários do governo norte-americano e dos organismos financeiros internacionais ali sediados - Fundo Monetário Internacional_FMI, Banco Mundial e o Banco Interamericano de Desenvolvimento_ BID, especializados em assuntos latinoamericanos, com o objetivo de avaliar as reformas econômicas empreendidas nos países da região. Embora tendo um formato acadêmico e sem caráter deliberativo e de sua natureza informal, acabaria por se revestir de significação simbólica, maior que a de muitas reuniões oficiais no âmbito dos foros multilaterais regionais. As conclusões dessa reunião é que se daria, a denominação informal de "Consenso de Washington" (BATISTA et al,1994).

As conclusões obtidas pelos especialistas do encontro foram de que a grave crise econômica, que os países enfrentavam, não tinha raízes externas, tais como a alta dos preços do petróleo e das taxas internacionais de juros, assim como a deterioração dos termos de intercâmbio entre os países desenvolvidos e subdesenvolvidos, mas basicamente a fatores internos.

A síntese das discussões propostas no Consenso Washington busca da disciplina fiscal, a priorização dos gastos públicos, a reforma tributária, a liberalização financeira, o regime cambial definido via mercado, a liberalização comercial, abertura para $O$ investimento estrangeiro, a privatização das empresas públicas (Estado mínimo), a desregulamentação e a garantia da propriedade intelectual. A adoção dessas medidas seriam condições sine qua non para os países interessados na obtenção de empréstimos e de ajuda financeira bilateral ou multilateral, mostrando o jogo de forças existente no cenário internacional, ou seja a capacidade de coerção de um país ou instituições por ele representadas (Messias, apud Silva 2008). Sendo assim, a solução estaria vinculada a reformas neoliberais, com a redução da participação do Estado na economia, superando o anacronismo dessas estruturas. Nesse sentido, a hegemonia do livre mercado só confirmou as indicações que o governo norte-americano vinha recomendando, por meio das diversas entidades, como condição necessária para a concessão de cooperação financeira externa, inclusive para os países do ex-mundo socialista (Messias, apud Silva 2008).

As forças produtivas básicas, tais como o capital, a tecnologia, a força de trabalho, a divisão do trabalho social, o 
mercado e o planejamento, entre outras, entram em contínua e ampla conjugação, desenvolvendo-se de forma intensiva e extensiva, ultrapassando fronteiras geográficas e históricas, regimes políticos e modos de vida, culturas e civilizações (IANNI, 1997, p.140).

O fim da monopolização do jogo estratégico pelas duas potências, Estados Unidos e União Soviética, estabelecida com o fim da Guerra Fria, fez com que os demais países tendessem a deslocar seus espaços de manobra para o campo econômico, alterando sua posição relativa na hierarquia de poder. $\mathrm{Na}$ medida em que já estavam em evidência diversos pólos dinâmicos mundiais, como a economia norte-americana, a Europa, que já consolidava seu processo de unificação, e o Japão, articulando boa parte da economia dos países da Ásia, intensificaram seus fluxos de comércio e, principalmente de capital, ampliando ainda mais o processo de integração da economia mundial. A busca do equilíbrio de forças e a necessidade de fortalecimento ante o acirramento $\mathrm{da}$ concorrência tecnológica, o aumento dos fluxos financeiros internacionais e a busca de novos mercados desencadearam a formação dos blocos econômicos como: a União Europeia, o Mercado Comum do Cone Sul (Mercosul), o Pacto Andino, o Tratado de Livre Comércio da América do Norte (NAFTA), a Cooperação Econômica da Ásia e Pacífico (APEC), a Associação das Nações do Sudoeste Asiático (ASIAN), entre outros.
Um ponto importante é que os blocos não são homogêneos, no que se refere à estrutura, composição, objetivos, até pelas razões que proporcionaram o processo de unificação, seja político, econômico ou puramente comercial. A União Europeia formou-se num amplo processo de discussão, que se iniciou no fim da Segunda Guerra Mundial e pode ser considerada realmente como uma integração na verdadeira acepção da palavra, abrangendo os níveis político, econômico e social (OSTRY,1994).

Apesar dos avanços obtidos, principalmente pela efetiva elevação do fluxo de comércio intra e extrabloco, a chegada de diversas empresas multinacionais, que operam nos mais variados setores, dinamizando muito a economia da região, observamos que a abertura comercial e a desregulamentação generalizada da economia agravaram sua vulnerabilidade externa.

O fluxo comercial intra-bloco na América Latina tem se mantido estável, apresentando pequenas variações na última década (CEPAL, 2012). Os fluxos de investimento estrangeiro direto vêm apresentando um crescimento importante nos países da América Latina, canalizados principalmente para Argentina, Brasil e México, em decorrência dos processos de privatização ocorridos nos anos 1990, atraídos também pela relativa estabilidade, seu vasto mercado consumidor $e$ as perpectivas de baixo crescimento nas economias desenvolvidas.

Tabela 1 - Investimento Estrangeiro Direto: 2004-2011 (em milhões de dólares)

\begin{tabular}{|l|l|l|l|l|l|l|l|l|}
\hline & 2004 & 2005 & 2006 & 2007 & 2008 & 2009 & 2010 & 2011 \\
\hline & & & & & & & & \\
América Latina & 47966.0 & 54694.9 & 29327.8 & 89144.3 & 93847.8 & 67925.4 & 73341.6 & 122783.7 \\
\hline
\end{tabular}

Fonte: CEPAL, 2012. 
Verificou-se que existe uma elevação dos investimentos diretos na América Latina, de forma contínua até 2008, num volume aproximado de US\$ 94 bilhões, queda de $27,6 \%$ em 2009, recuperando-se em 2010, recebendo US\$ 74 bilhões e obtendo um aumento de 67,41\% em 2001 em relação ao ano anterior, totalizando US\$ 122,7 bilhões (CEPAL: 2012). Tal elevação pode ser explicada pelo baixo nível de crescimento obtido nas economias desenvolvidas, que determinou uma reversão do fluxo monetário para alguns países da América Latina que apresentam os níveis mais expressivos de crescimento. Uma questão importante é quando houver uma recuperação dos principais mercados, se estes recursos serão redirecionados ou permanecerão na região.

É preocupante, porém, que, como se tratam de empresas prestadoras de serviços, sua arrecadação ocorre somente nos mercados internos, pois elas não são captadoras de recursos em moeda estrangeira. Caso esses recursos fossem direcionados para a indústria que poderia gerar produtos exportáveis, as dificuldades em relação à balança comercial e o nível de reservas cambiais seriam atenuados. No entanto, esses investimentos que são realizados no setor de serviços, já no início do processo, afetam negativamente a balança comercial, pois boa parte dos equipamentos e da tecnologia utilizada provém da matriz, além dos técnicos que são transferidos. Outro ponto importante é que, no momento do envio dos lucros obtidos e do pagamento do principal, pode gerar uma certa instabilidade no tocante às divisas internacionais, aumentando ainda mais sua vulnerabilidade em relação ao sistema financeiro internacional. O desafio da América Latina é imenso, pois além de erradicar a pobreza existente e reduzir as disparidades de renda existentes em cada país / região, integrando-se ao eixo dinamico da economia mundial, superando o modelo histórico de exportador de commodities, agregando mais valor aos seus produtos, criando condições macroeconômicas favoráveis que estimulem o crescimento auto-sustentado, que seria fundamental para superar esses problemas estruturais.

\section{Indicadores socioeconomicos da América Latina}

No período compreendido entre 2000 e 2007, em sua primeira metade (tabela 2), a variação do Produto Interno Bruto (PIB), os resultados foram bastante ruins. Verificou-se que apenas México, Chile e o Brasil, com taxas bem modestas, apresentaram taxas de crescimento positivas. A segunda metade do período coincide com $\mathrm{O}$ melhor ciclo econômico dos últimos 40 anos, registrando elevadas taxas de crescimento, baixas taxas de desemprego e inflação, fluxo de investimento e comercial em expansão. Quase metade do crescimento mundial é reflexo dos grandes países emergentes: Brasil, Rússia, Índia e China, denominados de BRIC's (Messias \& Silva, 2010). 
Tabela 2 - Indicadores Taxa de Crescimento do Produto Interno Bruto_PIB: 2000-2007

\begin{tabular}{|l|l|l|l|l|l|l|l|l|}
\hline PAÍS & $\mathbf{2 0 0 0}$ & $\mathbf{2 0 0 1}$ & $\mathbf{2 0 0 2}$ & $\mathbf{2 0 0 3}$ & $\mathbf{2 0 0 4}$ & $\mathbf{2 0 0 5}$ & $\mathbf{2 0 0 6}$ & $\mathbf{2 0 0 7}$ \\
\hline Argentina & $-0,8$ & $-4,4$ & $-10,9$ & 8,8 & 9,0 & 9,2 & 8,5 & 8,6 \\
\hline Bolívia & 2,5 & 1,7 & 2,5 & 2,7 & 4,2 & 4,0 & 4,6 & 3,8 \\
\hline Brasil & 4,3 & 1,3 & 2,7 & 1,1 & 5,7 & 2,9 & 3,7 & 5,3 \\
\hline Chile & 4,5 & 3,4 & 2,2 & 3,9 & 6,0 & 5,7 & 4,0 & 5,3 \\
\hline México & 6,6 & 0,0 & 0,8 & 1,4 & 4,2 & 2,8 & 4,8 & 3,3 \\
\hline Paraguai & $-3,3$ & 2,1 & 0,0 & 3,8 & 4,1 & 2,9 & 4,2 & 5,5 \\
\hline Uruguai & $-1,4$ & $-3,4$ & $-11,0$ & 2,2 & 11,8 & 6,6 & 7,0 & 7,5 \\
\hline Venezuela & 3,7 & 3,4 & $-8,9$ & $-7,8$ & 18,3 & 10,3 & 10,3 & 8,5 \\
\hline América Latina & $\mathbf{3 , 9}$ & $\mathbf{0 , 3}$ & $\mathbf{- 0 , 4}$ & $\mathbf{2 , 2}$ & $\mathbf{6 , 2}$ & $\mathbf{4 , 7}$ & $\mathbf{5 , 6}$ & $\mathbf{5 , 6}$ \\
\hline
\end{tabular}

Fonte: CEPAL, 2008.

Aliando-se ao cenário externo bastante favorável anterior a crise financeira|, verificou-se uma melhor qualidade dos indicadores macroeconômicos da região, culminando com taxas de crescimento médio superiores a $5 \%$, tendo a Argentina, Uruguai e Venezuela atingindo média de $8 \%$ de crescimento em 2007. Cabe ressaltar que esse bom desempenho foi proporcionado pela elevação da demanda e dos preços de energia, alimentos e outros produtos básicos que impulsionaram as exportações da região (Messias \& Silva, 2010).

Nas contas externas, entre 2003 e 2007, de forma agregada, houve superávit no saldo das transações correntes do balanço de pagamentos. No entanto, a partir de 2008, o saldo tornou-se negativo, diante da reversão de crescimento das importações e exportações, assim como tivemos também o forte impacto da queda do preço dos produtos primários, em função da retração econômica da Europa e dos Estados Unidos.

No caso do Brasil, ao perceber o impacto profundo da crise internacional na saúde financeira do país, início de 2009, o governo federal anunciou que adotaria uma política fiscal anticíclica. Porém, efetivamente, os instrumentos mais utilizados estão relacionados à política monetária e à de crédito. O estímulo fiscal foi reduzido, concentrado na renúncia de receitas e focado em alguns setores, principalmente $\mathrm{O}$ automobilístico, ao contrário das outras economias emergentes, que privilegiou o incremento dos investimentos fixos governamentais. Estas medidas ajudaram na recuperação do consumo e da própria economia, em que pese o bom desempenho dessas duas variáveis macroeconômicas A crise financeira global virou uma crise de crédito no Brasil. As reações monetárias tiveram mais dimensão e impacto na economia do que as fiscais, mas o crédito se tornou um elo comum entre elas (Afonso, 2012).

Contextualizando, o crédito experimentou forte expansão no meio da década: estava abaixo de $25 \%$ do PIB no meio de 2004 e cresceu 13 pontos do produto em apenas quatro 
anos (chegou a 38\% do PIB em julho de 2008). No mesmo período, taxas de juros recuaram e os instrumentos (e mesmo os atores) foram mudando sensivelmente - com destaque para o crédito pessoal, puxado pela figura do consignado (vinculado aos salários) (Afonso,2012, pag.8). O crédito teve múltiplos e relevantes papéis no comportamento mais recente da economia. Primeiro, ele contribuiu fortemente para o crescimento acelerado que a produção brasileira experimentou até o terceiro trimestre de 2008, acima de seu padrão histórico mais recente, de modo que se expandia na véspera da crise numa velocidade de três a dez vezes maiores que o PIB. Segundo, quando uma súbita crise de confiança parou o crédito, ele foi decisivo para o país mergulhar num período recessivo, que foi o mais profundo desde os anos 80, mas também um dos mais curtos. Terceiro, para uma rápida saída e aceleração progressiva e contínua da produção, a partir de meados de 2009, o crédito foi imprescindível (Afonso, 2012, pag.8).

Tabela 3 - Indicadores Taxa de Crescimento do Produto Interno Bruto_PIB: 2007 a 2012

\begin{tabular}{|l|l|l|l|l|l|l|}
\hline PAÍ́ & $\mathbf{2 0 0 7}$ & $\mathbf{2 0 0 8}$ & $\mathbf{2 0 0 9}$ & $\mathbf{2 0 1 0}$ & $\mathbf{2 0 1 1}$ & $\mathbf{2 0 1 2}$ \\
\hline Argentina & 8,6 & 6,8 & 0,9 & 9,2 & 8,9 & 2,0 \\
\hline Bolívia & 3,8 & 6,1 & 3,4 & 4,1 & 5,2 & 5,0 \\
\hline Brasil & 5,3 & 5,2 & $-0,3$ & 7,5 & 2,7 & 1,6 \\
\hline Chile & 5,3 & 3,7 & $-1,7$ & 5,2 & 6,1 & 6,0 \\
\hline México & 3,3 & 1,2 & $-6,3$ & 5,6 & 3,9 & 4,0 \\
\hline Paraguai & 5,5 & 5,8 & $-3,8$ & 13,1 & 4,4 & $-2,0$ \\
\hline Uruguai & 7,5 & 8,6 & 2,6 & 8,9 & 5,7 & 3,5 \\
\hline Venezuela & 8,5 & 5,3 & $-3,2$ & $-1,5$ & 4.2 & 5,0 \\
\hline América Latina & $\mathbf{5 , 6}$ & $\mathbf{4 , 0}$ & $\mathbf{- 2 , 0}$ & $\mathbf{6 , 0}$ & $\mathbf{4 , 3}$ & $\mathbf{3 , 2}$ \\
\hline
\end{tabular}

Fonte: CEPAL, 2012.

A tabela 3, que apresenta dados entre 2007 e 2012, foi criada para destacar o forte impacto da crise financeira internacional na economia, mais especificamente, para os países da America Latina, que obrigou muitos países a realizarem políticas restritivas, pois eles estão enfrentando diversos tipos de choques adversos: a redução do preço de alguns itens importantes de exportação, incerteza e desaceleração do crescimento econômico nos países desenvolvidos e também da China, que representa um país muito importante no cenário atual.

Os indicadores de emprego apresentaram uma pequena recuperação. A taxa de ocupação subiu $0,5 \%$ ao ano a partir de 2003, as taxas de desemprego giraram em torno de $8 \%$, os salários, no entanto, cresceram num ritmo menor, o que significa que as vagas criadas foram de baixa qualificação. As políticas anticíclicas adotadas pelos governos (fiscal, crédito e monetária) 
ajudaram a manter a taxa de desemprego neste patamar, porém não é npossível prever até quando elas possam ser mantidas.

Em pouco mais de dois terços do tempo previsto, cinco países já atingiram o objetivo de reduzir a miséria pela metade - Brasil, México, Chile, Equador e Panamá. Segundo estimativas de Cepal, caso não ocorresse retração no fluxo de capitais internacionais para a região, uma taxa média de crescimento de $1,1 \%$ ao ano permitirá que todos os países alcancem as metas estabelecidas nos objetivos do milênio. No entanto, não foi o que ocorreu, houve uma retração em 2009 e 2010, recuperando-se em 2011, com o ingresso de US \$ 124 bilhões neste ano (Cepal, 2012).

Entre os biênios 1990-1991 e 20022003, o gasto social por habitante cresceu $39 \%$, passando da média de 440 para 610 dólares. Esses recursos foram direcionados nas áreas de seguridade social, assistência social e na educação. No inicio dos anos noventa registrou-se um aumento dos gastos sociais em relação ao gasto público total, que passou de $45,7 \%$ em $1991-1992$ para 59,3\% em 2001-2002 e 62,6\% entre 2009-2010, o que mostra os impactos positivos das Políticas Sociais na redução da pobreza e na criação de oportunidades de inserção socioeconômica.

\section{Considerações finais}

A manutenção da melhoria das condições socioeconômicas vigentes nos países da América Latina decorreu da expansão dos gastos sociais, pela implementação de políticas sociais focadas nas camadas marginalizadas da população e também pela adoção de políticas compensatórias (fiscal, monetária e de crédito) por parte do Estado com o objetivo de manter os níveis de demanda interna existentes em cada economia da região e consequentemente do emprego e da renda.
A redução dos níveis de pobreza ocorreu, em parte, pelo crescimento econômico acumulado entre 2000 e 2008 e uma pequena recuperação em 2010 e 2011, que proporcionou a ampliação de oportunidades de melhoria de vida, ainda que insuficientes para atender o déficit social existente, mas, mantendo um processo contínuo de melhoria neste sentido.

A aplicação dos programas de transferência de renda condicionada aplicados pelos governos do México, Brasil e Chile, que se destacaram com os melhores indicadores sociais, mostram a importância do Estado e de suas políticas compensatórias como atenuadores das crises sociais e redução do nível de pobreza - não se restringindo apenas à uma visão meramente utilitarista da economia, que gera um forte darwinismo social, proposto pelo Consenso de Washington.

A instabilidade financeira, decorrente da crise no mercado de hipotecas de alto risco dos bancos de investimento dos Estados Unidos, gerou graves problemas de liquidez e de oferta de crédito nos mercados internacionais, o que afetou drasticamente as economias desenvolvidas e as perspectivas de crescimento e de investimento, retraiu o otimismo existente no período pré-crise.

Embora os países da América Latina tenham diversificado suas exportações, principalmente o México e os países da América do Sul, já que boa parte dos produtos é direcionada para países asiáticos, estão sentindo o impacto da retração econômica internacional, através da queda nas exportações, combinados a redução do preço de alguns itens exportáveis, principalmente commodities.

Os fluxos de investimentos internacionais continuam estáveis, para as principais economias da região, embora não saibamos se é algo durável ou apenas os investidores aguardam melhores 
oportunidades com a recuperação das economias desenvolvidas, que devido ao elevado grau de endividamento e de desemprego não são atrativos no momento.

Em momentos de crise, como o atual, é comum haver questionamentos sofre a efetividade das despesas sociais, como se a evolução econômica não dependesse também de uma estrutura social equilibrada e bem preparada para enfrentar os novos desafios, principalmente por esse momento de intensas mudanças tecnológicas e sociais.

É fundamental que os recursos direcionados as ploiticas sociais sejam aplicados de forma eficaz, nos moldes da governança corporativa, com a participação efetiva dos atores sociais envolvidos, com transferencia e equilíbrio, pois assim constituem investimento e não custo, uma vez que trarão frutos positivos para os beneficiados e também para o tecido social e econômico de uma forma geral.

Sendo assim, a manutenção do desenvolvimento socioeconômico necessário para contunuar reduzindo os níveis de pobreza e ampliando novas oportunidades de inserção na economia de forma positiva requer que o processo de integração social e econômico possam andar paralelamente, de forma que os benefícios certamente seriam maiores, através da sinergia entre ambos. Esta constitui uma pauta que deve ser definida como prioridade, promovendo assim uma forma mais abrangente de integração econômico-social para a América Latina

\section{Referências Bibliográficas}

1. ABRANCHES, S. H. et. al. Política social e combate à pobreza, $3^{\circ}$ ed., Jorge Zahar Editor, RJ. 1994.

\section{AFONSO, J.R., Fiscalidade Crédito e Crise} no Brasil: Diagnóstico e Proposições, Estudos Fundap (4), fevereiro de 2012.

3. AKTOUF, O. A administração entre a tradição e a renovação, Editora Atlas, S.P., 1996.

4. BATISTA, P. N. et.al. Em defesa do interesse nacional desinformação e alienação do patrimônio público, SP, Paz e Terra, 1994. 5. CEPA, ESTUDIO ECONÓMICO DE AMÉRICA LATINA Y EL CARIBE 2007 2008, 2008.

6. CEPA, ESTUDIO ECONÓMICO DE AMÉRICA LATINA Y EL CARIBE 2012, 2012.

7. CEPAL, INSTITUICIONES DE LA POLITICA SOCIAL: OBJETIVOS, PRINCIPIOS Y ATRIBUTOS. Informes e estudios especiales, 2006.

8. CEPAL, PANORAMA SOCIAL DA AMERICA LATINA 2012, 2012.

9. CEPAL. PANORAMA DE LA INSERCIÓN INTERNACIONAL DE AMÉRICA. Latina y el Caribe, Tendencias 2008, 2007.

10. CEPAL, VISIONES DEL DESARROLLO EN AMERICA LATINA AMÉRICA, 2007.

11. GARSCHAGEN, S., RESGATE SOCIAL AVANÇA NA AMÉRICA LATINA, Revista Desafios. dez/ 2007. 
12. IANNI, O. Teorias da globalização, $4^{\mathrm{a}}$ ed., Ed. Civilização Brasileira, R. J. 1997.

13. LODI, J.B., Governança Corporativa: $\mathrm{O}$ Governo da Empresa e o Conselho da Administração, Campus, R.J., 2000.

14. MESSIAS, J. F. \& SILVA, J. U., Políticas

Sociais Evolução Desenvolvimento Sócio Econômico da América Latina: 1998 a 2008, 15. IV Seminário Nacional de Pesquisa Universidade Nove de Julho, 2010. p. 333341.

16. MESSIAS, J. F., O Papel das Intituições na Construção do Século XXI nas Visões da Nova Economia e das Relações Internacionais e Comércio Exterior, in 17. SILVA, J. U. (org), Gestão das Relações Econômicas Internacionais, Editora Cengage, São Paulo, 2008. p.185-200.

18. OSTRY. S. A nova ordem mundial e a tendência à regionalização. In A nova ordem mundial em questão. VELLOSO, J.P.R.; MARTINS, L. José Olympio Editora, p. 362400, 1994.
19. BRESSER-PEREIRA, L.C. ESTRATÉGIA NACIONAL E DESENVOLVIMENTO. REVISTA DE ECONOMIA POLÍTICA, V. 26, N. 2 (1023), P. 203-30, ABRIL-JUNHO 2006. 20. PINHEIRO, V.C. Modelos de desenvolvimento e políticas sociais na América Latina em uma perspectiva histórica. Planejamento e Políticas Públicas, n. 12, jundez 1995.

21. POCHMANN, M. Políticas de emprego e renda no Brasil. In Bógus \& Paulino, políticas de emprego, políticas de população e direitos sociais, 1997.

22. POCHMANN, M., Vulnerabilidades sociais no capitalismo. In Pesquisa \& Debate - PUC/SP, v. 8, n¹2, 1997.

23. RAWLS, J. Uma teoria da justiça. São Paulo: Editora Martins Fontes, 1997

24. TÔRRES, O. de L. S., A noção sócioeconômica da pobreza, São Paulo: ESP/FGV, 1985.

25. TÔRRES, O. de L. S., Populações e famílias, São Paulo: ESP/FGV, 1987. 